\title{
Reaction of Naphthalene-2,3-Dicarboxaldehyde with Enkephalins for LC-Fluorescence and LC-MS Analysis: Conformational Studies by Molecular Modeling and H/D Exchange Mass Spectrometry
}

\author{
Marlène Lacroix, Jean-Christophe Garrigues, and François Couderc \\ Laboratoire des Interactions Moléculaires et Réactivité Chimique et Photochimique, Université Paul Sabatier, \\ Toulouse, France
}

\begin{abstract}
A new labeling method compatible with both laser-induced fluorescence (LIF) and MS detection for enkephalins, which uses naphthalene-2,3-dicarboxaldehyde (NDA) and a new nucleophilic agent ( $\mathrm{N}, \mathrm{N}$-dimethylaminoethanethiol) is described. When the derivative is separated via reverse phase HPLC and detected via MS, two different peaks with similar exact mass but different fluorescence and fragmentation properties are obtained. To interpret these results, molecular modeling and $\mathrm{H} / \mathrm{D}$ exchange mass spectrometry studies were investigated to test the hypothesis that the peak obtained by LC/LIF/MS analysis depends on the site of protonation of the labeled enkephalins. The peptides labeled with NDA and N,Ndimethylaminoethanethiol were separated on a reverse phase C18 column with a gradient of aqueous $0.1 \%$ formic acid and acetonitrile. In mass spectrometry, two peaks are observed with the same exact mass for each molecule while only one peak is detected using fluorescence. Tandem mass spectrometry experiments of ion $\mathrm{m} / \mathrm{z} 809.5$ were performed on each chromatographic peak; the first peak (which is not observed by LIF detection) gives a fragment corresponding to the loss of the aminothiol side chain while no fragmentation is observed on the second peak, which was detected by fluorescence. The hypothesis is that each peak represents the labeled enkephalin with different sites of protonation. According to this hypothesis, three fundamental conformations that were closed to the unlabeled leucine-enkephalin were obtained by molecular modeling: a $\beta$-turn like conformation with two hydrogen bonds, a $3_{10}$-helix with an $\mathrm{H}$ bond, and finally, the extended form without any intramolecular interactions. H/D exchange mass spectrometry experiments with $D_{2} \mathrm{O}$ and $d_{2}$ formic acid as eluent was used to determine which conformation is involved in each peak. (J Am Soc Mass Spectrom 2007, 18, 1706-1713) @ 2007 American Society for Mass Spectrometry
\end{abstract}

$\mathrm{E}$ nkephalins are opioid peptides discovered by Hughes et al. in 1975 [1] with analgesic properties similar to that of morphine. The two enkephalins, leucine enkephalin (Leu-Enk) and methionine-enkephalin (Met-Enk) are pentapeptides, which differ at the C-terminal function (Tyr-Gly-Gly-Phe-Leu or Met) and act as neurotransmitters and neuromodulators [2]. These compounds exert a profound influence on many physiological and pathological states such as pain transmission, addiction, and dementia [2-4]. Opioid peptide levels are typically measured by radioimmunoassay (RIA), enzyme-linked immunoassay (ELISA), or radioreceptorassay (RRA) [5, 6]. However, these modes of quantitation require a large sample volume and are reported to be less sensitive than chromatographic methods coupled with elec-

Address reprint requests to Dr. F. Couderc, Laboratoire des Interactions Moléculaires et Réactivité Chimique et Photochimique, ERT 1046, CNRS UMR 5623, Université Paul Sabatier, 31062 Toulouse, France. E-mail: couderc@chimie.ups-tlse.fr trochemical detection [7]. The two most common methods for quantitation are capillary electrophoresis (CE) and high-performance liquid chromatography (HPLC) [8] coupled to electrochemical detectors [7], UV detectors [9], laser-induced fluorescence (LIF) detectors [10], or mass spectrometry detection [11, 12].

Stobaugh et al. have developed chromatographic methods to monitor leucine-enkephalin in biological samples using fluorescence detection. These workers derivatized the peptides with the fluorogenic dye naphthalene-2,3dicarboxaldehyde (NDA) [13-15], which is an analog of the popular fluorogenic agent o-phthaldehyde (OPA) [16]. The dye reacts in the presence of a nucleophilic agent such as cyanide ion $\left(\mathrm{CN}^{-}\right)$or a thiol on the primary amine of the N-terminal function of peptides to give stable compounds which fluoresce with excitation of 420 to 440 nm [17]. Recently, two different analytical methods for quantifying a model of opioid peptide (Tyr-D-Ala-GlyPhe-D-Leu) and two cyclic peptidic prodrugs in rat 
plasma were compared; HPLC with fluorescence detection via NDA/CN derivatization and mass spectrometry with electrospray ionization (ESI) coupled to HPLC [18]. These two methods present both advantages and drawbacks; when LIF is employed, the enkephalins have to be labeled, leading to less sensitive limits of detection, while for MS, a specific internal standard is needed for quantitation [18].

This paper describes our studies in the use of NDA and an aminothiol as a derivatization process for both fluorescence and MS quantitation of enkephalins. This process would enable us to perform an HPLC separation with both LIF and mass spectrometry (MS) detection to optimize the identification and quantification of enkephalins in biological samples. To use a common separation for the two detection methods, the enkephalins would have to be labeled to be fluorescent for LIF detection and the labeled peptides must have an ionizable site to provide ions for MS detection. We derivatized enkephalin with NDA with a new nucleophilic agent, N,N-dimethylaminoethanethiol (Me-AT), which is easily ionizable due to its tertiary amine function [19]. A number of experiments are described and the results are interpreted via molecular modeling and H/D exchange in mass spectrometry.

\section{Experimental}

\section{Materials}

Leu-Enk, N,N-dimethylaminoethanethiol, potassium cyanide (KCN), NDA, formic acids, boric acid, and sodium tetraborate were purchased from Sigma-Aldrich Co. (St. Quentin Fallavier, France). Solvents were obtained from SDS (Aix en Provence, France) and deuterium oxide was obtained from Eurisotop (Gif sur Yvette, France).

\section{Peptide Labeling with NDA}

Enkephalin samples were labeled by adding $720 \mu \mathrm{L}$ of $10^{-5} \mathrm{M}$ peptide solution, $120 \mu \mathrm{L}$ of a $43 \mathrm{mM}$ solution of

(a)
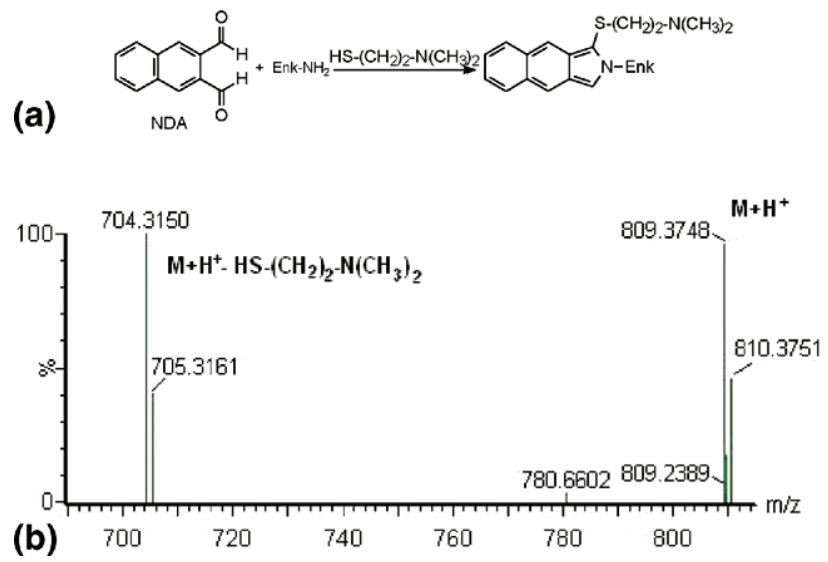

Figure 1. (a) Labeling reaction of enkephalins with NDA and Me-AT. (b) Mass spectrum of leucine-enkephalin labeled with NDA and Me-AT.

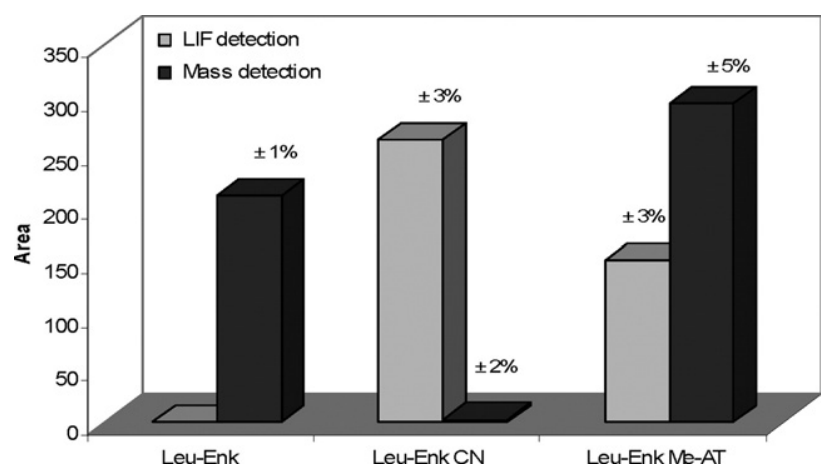

Figure 2. Comparative studies of equimolar solutions of native Leu-Enk, Leu-Enk labeled with NDA/CN and Leu-Enk derivatized with NDA/Me-AT in LC/LIF and LC/MS mode.

$\mathrm{N}, \mathrm{N}$-dimethylaminoethanethiol or potassium cyanide, $120 \mu \mathrm{L}$ of borate buffer ( $\mathrm{pH}$ 8.7), and $40 \mu \mathrm{L}$ of NDA (5 $\mathrm{mM}$ ). Samples were filtered with $0.45 \mu \mathrm{m}$ uptidisc Nylon filter (25 mm diameter; Waters, Guyaucourt, France) and kept for $2 \mathrm{~min}$ at room temperature before injection into the HPLC.

\section{HPLC Analysis}

HPLC analyses were run on a Dionex HPLC P680 pump (Dionex, Voisin Le Bretonneux, France) with an LC Packings Famos Autosampler (LC Packings, Dionex) and a Picometrics ZetaLIF laser-induced fluorescence detector equipped with a He-Cd $442 \mathrm{~nm}$ laser (Picometrics, Toulouse, France). The sample was separated with a Xbridge Shield RP18, $2.1 \times 100 \mathrm{~mm}, 3.5 \mu \mathrm{m}$ column (Waters Corporation, Milford, MA). A $375 \mu \mathrm{m}$ o.d. and $100 \mu \mathrm{m}$ i.d. fused silica capillary (Polymicro Technology, Phoenix, AZ) was connected to the output of the column. A window was burnt at $20 \mathrm{~cm}$ of the separation column to allow LIF detection. Eluents were HPLC quality and filtered with a $45 \mu \mathrm{m}$ uptidisc Nylon membrane $(4.7 \mathrm{~mm}$ diameter (Interchim, Montluçon, France). Flow rate was of $0.3 \mathrm{~mL} / \mathrm{min}$ and $10 \mu \mathrm{L}$ of the sample were injected on the following gradient: $\mathrm{t}=0 \mathrm{~min}$ to $\mathrm{t}=2 \mathrm{~min}, 80 \% \mathrm{H}_{2} \mathrm{O}$ acidified with $0.1 \%$ formic acid and $20 \%$ acetonitrile, $\mathrm{t}=15 \mathrm{~min} 20 \%$ $\mathrm{H}_{2} \mathrm{O}$ and $80 \%$ acetonitrile. Analyses were monitored by Chromeleon software 6.60 (Dionex).

$\mathrm{H} / \mathrm{D}$ exchange experiments were investigated using the same conditions as HPLC except that water and formic acid were substituted by deuterium oxide and formic acid $d_{2}$.

\section{Mass Spectrometry}

A Waters Q-TOf Ultima API mass spectrometer with an electrospray ionization source (ESI) in positive mode was directly coupled to the LIF detector. The capillary, cone and rf lens potentials were set to $3 \mathrm{kV}, 35 \mathrm{~V}$, and 40 $\mathrm{V}$, respectively. The source and desolvation temperature were set to $100^{\circ}$ and $120^{\circ} \mathrm{C}$ and the collision energy 
(a)

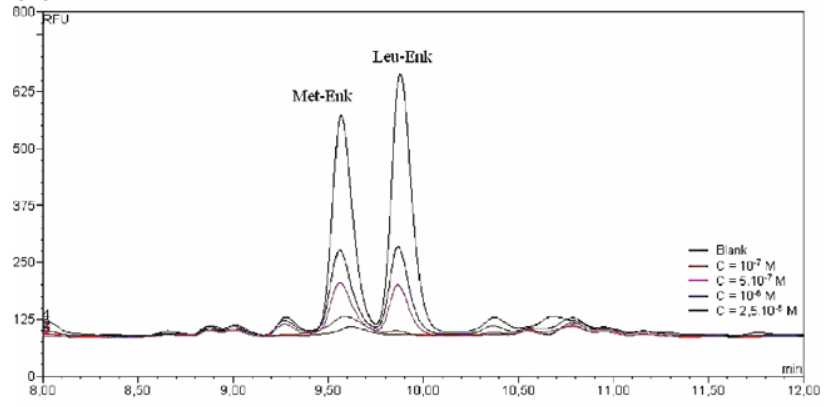

(b)

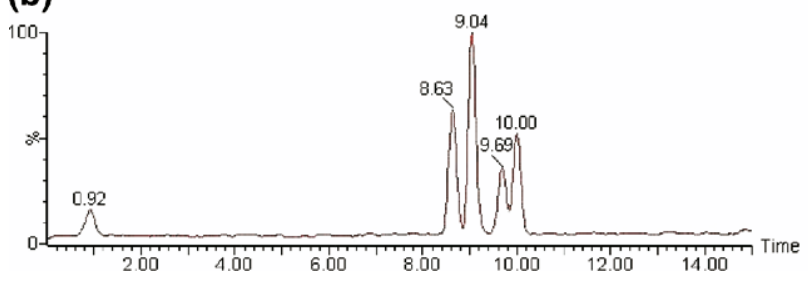

Figure 3. (a) Separation of labeled Met-Enk and Leu-Enk with LIF detection at different concentration. (b) Total ion current (TIC) of the two labeled enkephalins $\left(5 \times 10^{-6} \mathrm{~mol} / \mathrm{L}\right)$ obtained with mass spectrometric detection; tr 9.69 and 10.00 min correspond, respectively, to labeled Met-Enk and Leu-Enk detectable by fluorescence and tr 8.63 and 9.04 min have not been observed with the LIF detector but correspond to the masses of the labeled enkephalins.

was $10 \mathrm{eV}$ in TOF-MS mode or 15 to $60 \mathrm{eV}$ in TOF MS/MS mode, and a $9.1 \mathrm{kV}$ TOF potential was used. Analyses were monitored with MassLynx 4.0 software (Waters). To measure the exact mass, the spectrometer was calibrated with $\mathrm{H}_{3} \mathrm{PO}_{4}$ adducts and an impurity present in the eluent. In fact, the eluent was calibrated with $\mathrm{H}_{3} \mathrm{PO}_{4}$ and then each peak corresponding to the presumed labeled Leu-Enk was centered using the exact mass of the impurity.

\section{Molecular Modeling}

Molecular modeling of the protonated labeled Leu-Enk was investigated with Chem 3D software version 9.0 (ChemOffice Ultra 2005; Cambridge Software, Cambridge, MA). Energy minimization was performed with the semiempirical AM1 quantum mechanical calculations of the MOPAC server in the Chem 3D application, with a RMS gradient of 0.100 .

The calculated octanol/water partition coefficient $(\mathrm{C} \log \mathrm{P})$ was obtained with the C-Log P server of the ChemOffice Ultra 2005 application.
The formation enthalpies $\left(\Delta \mathrm{H}^{\circ} \mathrm{f}\right)$, expressed in Kcal/ mol, were calculated with AM1 server for each conformation. The hydrogen bonds were determined by measuring the distance [in Angstrom $(\AA)$ ] between the $\mathrm{N}-\mathrm{H}$ of amide bond and the $\mathrm{C}=\mathrm{O}$ of neighboring amide function.

\section{Results and Discussion}

\section{Labeling Studies of Enkephalins}

Enkephalins react with NDA and N,N-dimethylaminoethanethiol (Me-AT) to form a fluorescent benzisoindole derivative with a maximum absorbance at a wavelength of $442 \mathrm{~nm}$ and a maximum emission at $530 \mathrm{~nm}$. The monoisotopic molecular mass of these derivatives is 808.36 Da for Leu-Enk and 826.32 Da for Met-Enk, both labeled with NDA and Me-AT. Using ESI ${ }^{+}$, these molecules give the parent ion $(\mathrm{M}+\mathrm{H})^{+}$with a specific fragmentation with a loss of a neutral compound with a mass of 105.1 corresponding to the mass $^{\circ}$ of $^{\circ}$ the $^{\circ}$ aminothiol $^{\circ}$ (Figure ${ }^{\circ} 1$ ).

\section{Comparative Studies of the Labeling NDA/KCN and NDA/Me-AT}

To verify if this new labeling method gives a more ionizable molecule for mass detection, the NDA/ Me-AT labeled species (Leu-Enk Me-AT) was compared with native Leu-Enk and NDA/CN labeled Leu-Enk (Leu-Enk CN). Labeling conditions are the same for Leu-Enk Me-At and Leu-Enk CN. Ten $\mu \mathrm{L}$ of each compound is injected three times. By comparing the ion selected ${ }^{\circ}$ chromatograms $^{\circ}\left(\right.$ Figure $\left.^{\circ} 2\right),{ }^{\circ}$ for ${ }^{\circ} 10^{\circ} \mu \mathrm{L}^{\circ}$ of ${ }^{\circ}$ each compounds injected, the new labeling method gives a molecule that is more ionizable than native Leu-Enk while the labeling of NDA/CN is poorly ionizable. On the mass spectrum, the signal-to-noise ratios are $220 \pm$ $18,260 \pm 37$, and $10 \pm 1$ for NDA/Me-AT, native Leu-Enk, and NDA/CN labeling, respectively. Even if NDA/CN labeling gives a more fluorescent compound than the enkephalin labeled with NDA/Me-AT, this new labeling provides a good alternative to the combination of LIF and mass spectroscopy detection.

\section{HPLC/LIF Experiments}

The best separation of the enkephalins via HPLC using a C18 column was obtained with a gradient as de-

Table 1. Results of labelled enkephalins with LIF detection and MS detection

\begin{tabular}{|c|c|c|c|c|c|c|c|c|}
\hline & \multicolumn{4}{|c|}{ LIF detection } & \multicolumn{4}{|c|}{ MS detection } \\
\hline & $\operatorname{Tr}(\min )$ & $\mathrm{LOD} \mu \mathrm{mol} / \mathrm{L}(\mathrm{S} / \mathrm{N}=3)$ & Linearity & $\mathrm{R}^{2}$ & $\operatorname{Tr} 1$ (min) & $m / z 1$ & $\operatorname{Tr} 2$ (min) & $m / z 2$ \\
\hline Met-Enk & 9.87 & 0.09 & $y=2 E+7 x+4,9$ & 0.995 & 8.63 & $837.6 \& 722.6$ & 9.69 & 837.6 \\
\hline Leu-Enk & 9.55 & 0.10 & $y=2 E+7 x-1,9$ & 0.996 & 9.04 & $809.6 \& 704.6$ & 10.00 & 809.6 \\
\hline
\end{tabular}

Calibration range was $0.1 \mu \mathrm{mol} / \mathrm{L}-10 \mu \mathrm{mol} / \mathrm{L}$. 


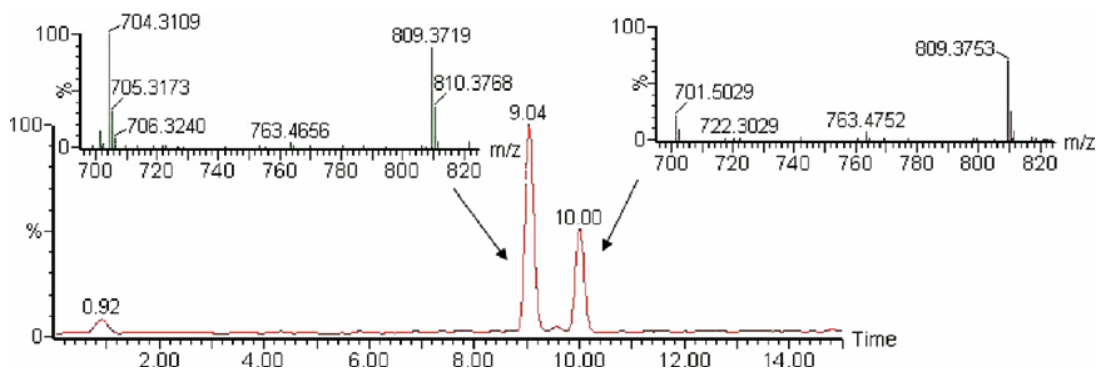

Figure 4. TIC of Leu-Enk labeled with NDA and Me-AT and mass spectrum of each peak observed: $\operatorname{tr}=9.04$ min spectrum with $\mathrm{M}+\mathrm{H}^{+}$ion and its fragment corresponding to the loss of aminothiol side chain, $\operatorname{tr}=10.00 \operatorname{min~} \mathrm{M}+\mathrm{H}^{+}$parent ion and no fragmentation.

scribed in the experimental section. A He-Cd $(442 \mathrm{~nm})$ LIF detector was used; as its wavelength is compatible with the maximum absorption of the labeled peptides. Fluorescent peaks were obtained at retention times of 9.55 and $9.87 \mathrm{~min}$ for Met-Enk and Leu-Enk labeled with ${ }^{\circ} \mathrm{NDA}^{\circ}$ and $^{\circ} \mathrm{Me}^{-\mathrm{AT}^{\circ}}{ }^{\text {respectively }}{ }^{\circ}\left(\text { Figure }^{\circ} 3 \mathrm{a} \text {. }\right)^{\circ}{ }^{\mathrm{T}}$ The limit of detection (LOD) was $8.6 \times 10^{-8} \mathrm{~mol} / \mathrm{L}$ for Met-Enk and $1.0 \times 10^{-7} \mathrm{~mol} / \mathrm{L}$ for Leu-Enk with a signal-to-noise of 3 for each enkephalin. The calibration curves $^{\circ}$ were ${ }^{\circ}$ linear ${ }^{\circ}$ and $^{\circ}$ are $^{\circ}$ presented $^{\circ}$ in $^{\circ}$ Table $^{\circ} 1$.

\section{Mass Spectrometry Detection}

When the Met-Enk and Leu-Enk derivatives are analyzed via mass spectrometry, the chromatogram contains four peaks for the $\mathrm{m} / \mathrm{z}$ corresponding to the

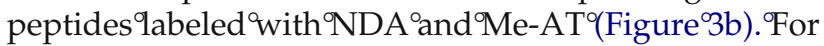
both peptides, the second eluted peaks correspond to the fluorescent compound detected with the LIF detector and the first peak presents another compound that does not fluoresce.

The retention times and their corresponding masses are $^{\circ}$ summarized ${ }^{\circ}$ in $^{\circ}$ Table $^{\circ} 1^{\circ}$ and $^{\circ}$ the $e^{\circ}$ mass $^{\circ}$ spectra $^{\circ}$ for

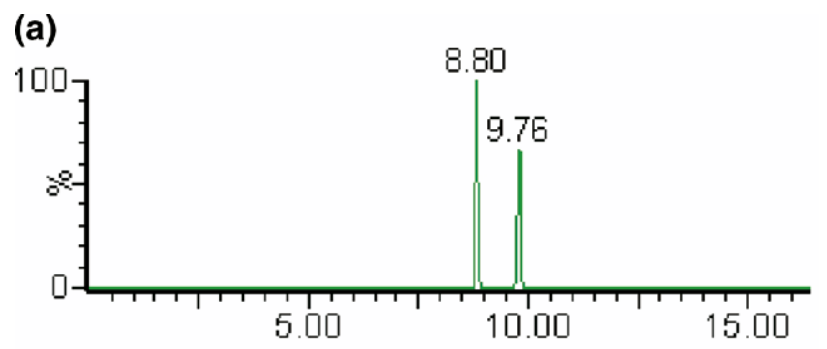

(b)

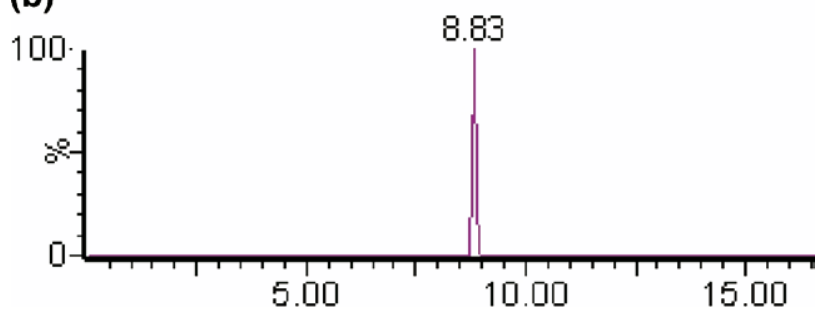

Figure 5. (a) Single ion monitoring (SIM) at $\mathrm{m} / \mathrm{z}=809.5$ of labeled Leu-Enk, (b) MS/MS chromatogram at $m / z=809.5$, collision energy of $30 \mathrm{eV}$. each peak were investigated. For Leu-Enk, the firsteluted peak (9.04 min, nonfluorescent) provides an exact mass at $m / z=809.3719$ with the specific fragmentation at $\mathrm{m} / z=704.5$ (loss of the aminothiol molecule). The second peak $\left(t_{r}=10.00 \mathrm{~min}\right)$ was detected by fluorescence and also provides a mass spectrum with the parent ion at an exact mass at $m / z=809.3753$ but without fragmentation at 704.5. The results for the labeled Met-Enk were similar, so further experiments were ${ }^{\circ}$ ly $^{\circ}$ performed ${ }^{\circ}{ }^{\circ}{ }^{\circ}$ Leu-Enk ${ }^{\circ}$ (Figure $\left.{ }^{\circ} 4\right)$.

The mass difference between these two $\mathrm{m} / \mathrm{z}$ is 3.6 $\mathrm{mDa}$; this is small enough to conclude that the peaks correspond to the same molecule (the NDA-aminothiollabeled ${ }^{\circ}$ molecule $)^{\circ}$ as $^{\circ}$ they ${ }^{\circ}$ have $e^{\circ}$ the ${ }^{\circ}$ same $^{\circ}$ mass $^{\circ}$ (Figure ${ }^{\circ} 4$ ).

MS/MS studies were investigated on each peak at the mass $m / z=809.5$ at collision energies varying from 15 to $60 \mathrm{eV}$. At a retention time of $9.04 \mathrm{~min}$, the fragment corresponding to the loss of the aminothiol side chain was observed until $40 \mathrm{eV}$ of collision energy while no fragmentation was obtained at any collision energies for the peak at $\mathrm{t}_{\mathrm{r}}{ }^{\circ}{ }^{\circ} 10.00^{\circ} \mathrm{min}^{\circ}$ (Figure ${ }^{\circ}$ ).

These experiments clearly indicate that if a labeled peptide is injected, two peaks are observed on the chromatogram from the mass spectrometer: the first one that is eluted is not fluorescent but gives the specific fragment corresponding to the loss of the aminothiol side chain while the second eluted peak is fluorescent but does not fragment even using MS/MS with $60 \mathrm{eV}$ collision energy.

From this data we suggest that there are two stable conformations of the peptide. The acidic eluent ionizes

Table 2. Molecular modeling results for the different conformations of labelled Leu-Enk

\begin{tabular}{|c|c|c|c|c|c|}
\hline \multirow[b]{2}{*}{ Conformation $^{a}$} & \multirow[b]{2}{*}{$\mathrm{Clog} \mathrm{P}^{\mathrm{a}}$} & \multirow{2}{*}{$\begin{array}{c}\Delta \mathrm{H}^{\circ} \mathrm{f} \\
\mathrm{kCal} / \mathrm{mol}^{\mathrm{a}}\end{array}$} & \multicolumn{3}{|c|}{$\mathrm{d}(\mathrm{C}=\mathrm{O} \ldots . . \mathrm{H}-\mathrm{N}) \AA^{\mathrm{a}}$} \\
\hline & & & $(2-4)^{b}$ & $(4-2)^{b}$ & $(1-3)^{b}$ \\
\hline$\beta$-turn ${ }^{c}$ & 4.0 & -1.98 & 2.16 & 2.29 & - \\
\hline $3_{10}-$ Helix $^{d}$ & 6.3 & -18.6 & - & - & 2.34 \\
\hline Extended $^{d}$ & 6.3 & -18.6 & - & - & - \\
\hline
\end{tabular}

${ }^{a}$ Calculations are described in the experimental section.

$\mathrm{b}(\mathrm{X}-\mathrm{Y})$ corresponds to the hydrogen bond between $\mathrm{C}=\mathrm{O}$ of the $\mathrm{X}^{\text {th }}$

$\mathrm{N}$-terminal amino acid and the $\mathrm{N}-\mathrm{H}$ of the $\mathrm{Y}^{\text {th }} \mathrm{N}$-terminal amino acid.

c Conformation obtained with $\mathrm{H}^{+}$on the benzisoindole amine.

${ }^{\mathrm{d} C}$ Conformation obtained with $\mathrm{H}^{+}$on the aminothiol side chain 

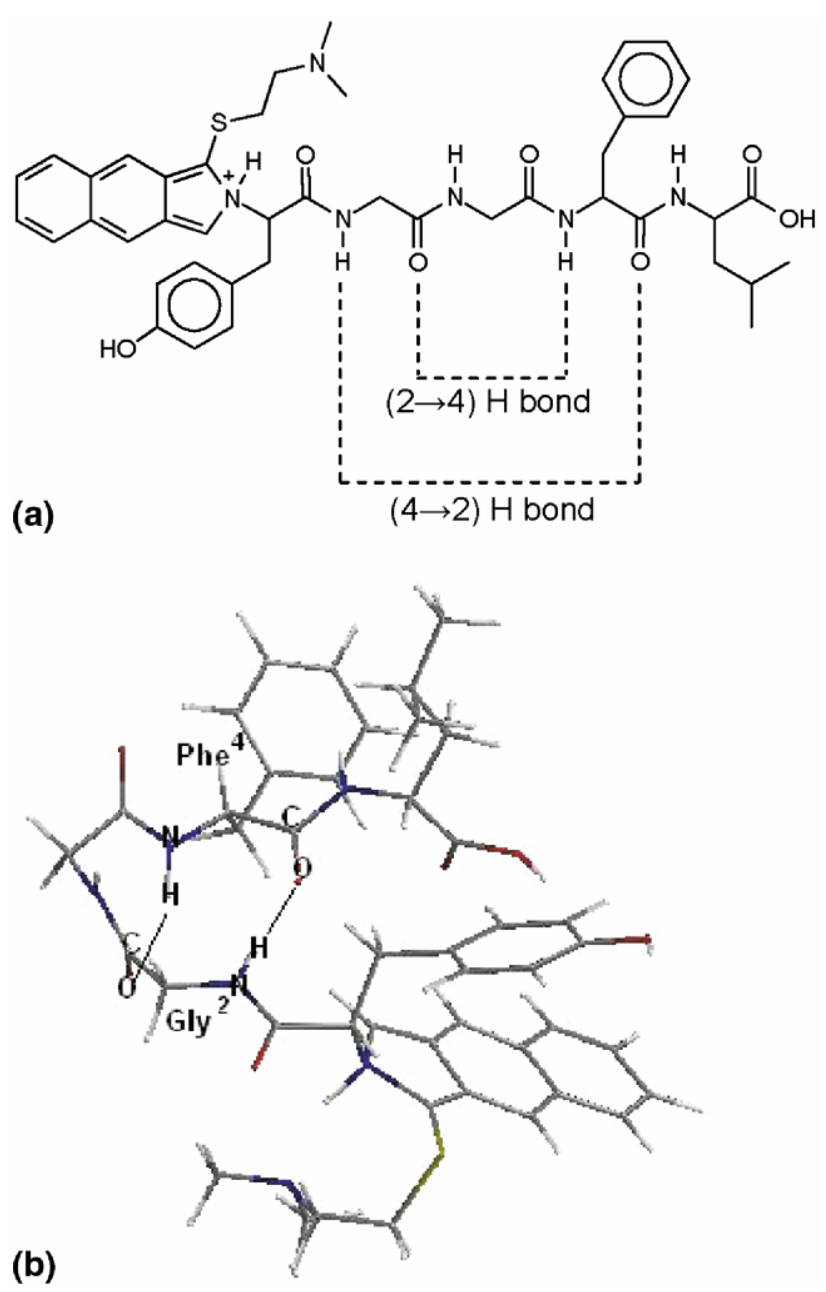

Figure 6. Molecular modeling of labeled Leu-Enk with $\mathrm{H}^{+}$fixed on the benzisoindole amine (a) 2-D structure with its schematic hydrogen bonds, (b) 3-D structure similar to the $\beta$-turn conformation with its two hydrogen bonds.

the labeled compound on two different sites, which modifies the spatial conformation of the two molecules. This difference between these two stable conformations could explain the difference of hydrophobicity and so the two retention times were observed in mass spectrometry.

We note that a proton can settle on several basic sites of the peptide; on the amine function on the benzisoindole ring, on the amine that is on the nucleophilic side chain, on the $S$ atom of the thioether, or on the amide function present in the Leu-Enk sequence. To verify these hypotheses, molecular modeling studies and H/D exchange experiments were performed.

\section{Molecular Modeling}

The labeled peptides have four types of protonation sites; the tertiary amine on the thioether side chain, the aromatic amine included in the benzisoindole ring, or the four amide functions corresponding to the peptidic bonds of the enkephalin, and the thioether function. Molecular modeling studies have been investigated on each of the possible protonatable sites. A hydrophobicity parameter ${ }^{\circ} \mathrm{Clog}^{\circ}$ was $^{\circ}$ calculated $^{\circ}\left(\right.$ Table $\left.^{\circ} 2\right),{ }^{\circ}$ and ${ }^{\circ}$ results show that two kinds of conformations exist; one conformation with ClogP close to 4 and the other around 6. As amine functions are more basic and therefore more easily protonatable than amide and thioether functions [20], 'we focused ${ }^{\circ}$ on two ${ }^{\circ}$ possible ${ }^{\circ}$ sites; 'tertiary ${ }^{\circ}$ mine ${ }^{\circ}$ on the aminothiol side chain and tertiary aromatic amine included in the benzisoindole ring.

ClogP calculations of were performed to determine the polarity of the molecules. It is well known that on a reverse phase HPLC, molecules are separated according to their polarities. If a specific molecule has a ClogP lower than another compound, this compound would be less retained on a C18 column than one that has a higher $\mathrm{C} \log \mathrm{P}$, and a correlation of $\mathrm{C} \log \mathrm{P}$ and the retention time can be investigated.

The peak at $t_{\mathrm{r}}=9.04 \mathrm{~min}$ represents Leu-Enk protonated on the amine included in the benzisoindole ring because $C \log P$ is 4.0 , while the peak at $t_{r}=10.00 \mathrm{~min}$ would be Leu-Enk protonated on the side chain for which $^{\circ} \mathrm{Clog}^{\circ}$ is $^{\circ} 6.3^{\circ}\left(\right.$ Table $\left.^{\circ} 2\right) .^{\circ}$ The $^{\circ}$ position $^{\circ}$ of $^{\circ}$ the protonation site involves the different hydrophobicity correlated with both retention and the conformations.

Three dimensional studies of the labeled Leu-Enk were investigated with respect to these two sites of protonation. In the literature, three fundamental 3D conformations have been characterized on these two endogenous opioid peptides using a variety of different methods ${ }^{\circ}$ such $^{\circ}$ as $^{\circ} \mathrm{FT}^{-\mathrm{IR}^{\circ} \text { and }}{ }^{\circ} \mathrm{NMR}^{\circ}$ spectroscopy ${ }^{\circ}[21,22]$, molecular ${ }^{\circ}$ modeling $^{\circ}[23-25]^{\circ}$, and $^{\circ}$ mass $^{\circ}$ spectrometry $\left[26,{ }^{\circ} 27\right] . .^{\circ}$ The $^{\circ}$ first $^{\circ}$ conformation $^{\circ}$ was $^{\circ}$ the $^{\circ}$ extended ${ }^{\circ}$ conformation, which can be stabilized by intermolecular hydrogen bonds. The second conformation is the $\beta$-turn folded form with two intramolecular hydrogen bonds; the $^{\circ}$ first $^{\circ}$ between $^{\circ} \mathrm{C}=\mathrm{O}^{\circ}\left(\mathrm{Tyr}^{\circ}[1]^{\circ}\right.$ and $^{\circ} \mathrm{N}-\mathrm{H}^{\circ}\left(\mathrm{Gly}^{\circ}[3]\right.$ and ${ }^{9} e^{\circ}$ second $^{\text {between }}{ }^{\circ} \mathrm{C}=\mathrm{O}^{\circ}\left(\mathrm{Phe}^{9}[4]^{\circ}\right.$ and $\mathrm{N}-\mathrm{H}^{\circ}\left(\mathrm{Tyr}^{\circ}[1]\right.$. The last conformation is the $3_{10}$-helix structure with an $\mathrm{H}^{\circ}$ bond ${ }^{\circ}$ between ${ }^{\circ} \mathrm{C}^{\circ}={ }^{\circ} \mathrm{O}^{\circ}\left(\operatorname{Tyr}^{\circ}[1]^{\circ}\right.$ and ${ }^{\circ} \mathrm{N}-\mathrm{H}^{\circ}\left(\mathrm{Gly}^{\circ}[3]^{\circ}[21\right.$, $28,29]$. These ${ }^{\circ}$ conformations have been ${ }^{\circ}$ characterized in aqueous solutions, DMSO, and a mixture of these two solvents ${ }^{\circ}[21] .^{\circ}$ Since $^{\circ} \mathrm{DMSO}^{\circ}$ has $^{\circ} \mathrm{a}^{\circ}$ similar $^{\circ}$ polarity $^{\circ}(\mathrm{P})^{\circ}$ as

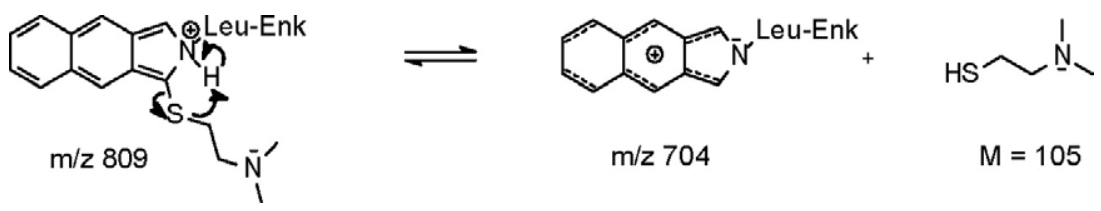

Figure 7. Mechanism proposed to interpret the fragmentation with the loss of the aminothiol side chain and the loss of fluorescence. 


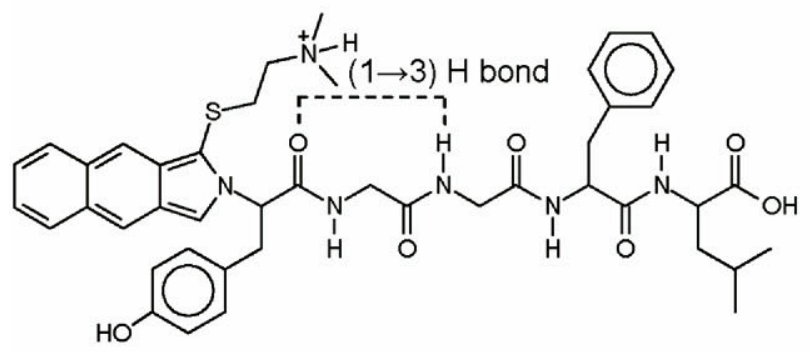

(a)

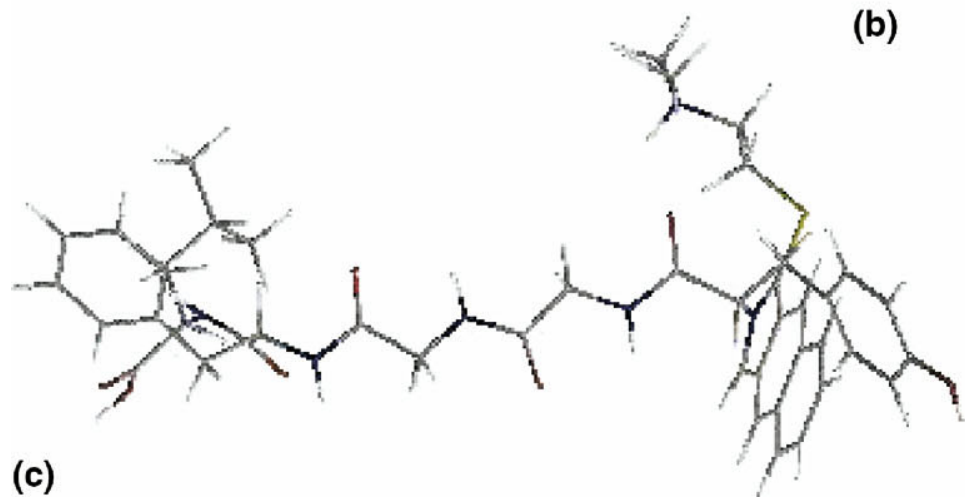

Figure 8. Molecular modeling of labeled Leu-Enk with $\mathrm{H}^{+}$fixed on the aminothiol side-chain. (a) 2-D structure with schema of its possible hydrogen bond, (b) 3-D structure representing the 310 -helix conformation with its hydrogen bond, (c) 3-D structure of the extended conformation. acetonitrile $\left(P=0.65 \mathrm{E}^{\circ} \mathrm{Al}_{2} \mathrm{O}_{3}\right.$ for acetonitrile and $P=$ $0.62 \mathrm{E}^{\circ} \mathrm{Al}_{2} \mathrm{O}_{3}$ for DMSO), the resulting conformations are comparable with those characterized in the previous conditions. In each case, the N-terminal function of these peptides is not involved in the hydrogen bonds; this observation leads us to suggest that the $\mathrm{N}$ primary labeling peptides would not dramatically influence conformations of the enkephalins.

When the proton is attached to the benzisoindole aromatic amine, molecular modeling gives a conformation of Leu-Enk stabilized by two hydrogen bonds, the first between ${ }^{\circ} \mathrm{C}=\mathrm{O}^{\circ}\left(\mathrm{Phe}^{\circ}[4]^{\circ}\right.$ and ${ }^{\circ} \mathrm{N}-\mathrm{H}^{\circ}\left(\mathrm{Gly}^{\circ}[2]^{\circ}\right.$ and ${ }^{\circ}$ the ${ }^{\circ}$ second between ${ }^{\circ} \mathrm{C}=\mathrm{O}^{\circ}\left(\mathrm{Gly}^{\circ}[2]^{\circ}\right.$ and ${ }^{\mathrm{N}} \mathrm{-} \mathrm{H}^{\circ}\left(\mathrm{Phe}^{\circ}[4]\right.$. The $^{\circ}$ distances ${ }^{\circ}$ of these ${ }^{\circ}$ bonds $^{\circ}$ are $^{\circ}$ listed $^{\circ}$ in $^{\circ}$ Table $^{\circ} 2^{\circ}$ with $^{\circ}$ the ${ }^{\circ}$ formation enthalpy calculations. We will call the previous conformation " $\beta$-turn" ${ }^{\circ}$ as $^{\circ}$ shown $^{\circ}$ in $^{\circ}$ Figure $^{\circ} 6$. $^{\circ}$ The ${ }^{\circ}$ literature indicates that the fluorescence quantum yield of indoles such as tryptophan is due to a hydrogen transfer from the amino function of the chromophore, which involves electron-deficient ${ }^{\circ}$ species ${ }^{\circ}$ in ${ }^{\circ}$ the $^{\circ}$ cycle $^{\circ}[30,31]$. In ${ }^{\circ}$ this ${ }^{\circ}$ case, the loss of fluorescence can be due to the desocialization of the electron when the proton is fixed on the amino function included in the aromatic benzisoindole ring. In fact, when this protonation occurs in the acidic eluant, the molecule loses its aromaticity as there is an electron deficiency that involves the fluorescence-quenching.

In addition, a fragmentation mechanism can be proposed. According to this correlation, a fragmentation can occur when the proton is fixed on the ring (i.e., when Leu-Enk is folded). In this conformation, the proton is closed to the sulfur atom of the aminothiol side-chain (3.0 $\AA$ ) and so a quick intramolecular rearrangement can be possible with the loss of the aminothiol $^{\circ}$ (Figure ${ }^{\circ}$ ).

When the proton is fixed on the amine function of the aminothiol side chain, two conformations present the Iowest $^{\circ}$ formation ${ }^{\circ}$ enthalpy $^{\circ}\left(\right.$ Table $\left.^{\circ}\right) .{ }^{\circ}$ The $^{\circ}$ first $^{\circ}$ one ${ }^{\circ}$ is

Table 3. Results of the H/D exchanged on each conformation with the average of the relative abundance of each mass and its variations

\begin{tabular}{ccccccc}
\hline & \multicolumn{2}{c}{$\operatorname{Tr}=9.04 \mathrm{~min}$} & & \multicolumn{2}{c}{$\operatorname{Tr}=10.00 \mathrm{~min}$} \\
\cline { 2 - 3 } \cline { 5 - 6 } & $\begin{array}{c}\text { Relative } \\
\text { abundance } \%\end{array}$ & $\begin{array}{c}\mathrm{CV} \\
(n=3)\end{array}$ & & $\begin{array}{c}\text { Relative } \\
\text { abundance } \%\end{array}$ & $\begin{array}{c}\mathrm{CV} \\
(n=3)\end{array}$ \\
\hline \hline 812 & 23.7 & 3.5 & & - & - \\
813 & 57.9 & 6.8 & & 6.6 & 1.3 \\
814 & 100.0 & - & & 27.2 & 2.7 \\
815 & 73.7 & 5.7 & & 69.7 & 3.5 \\
816 & 32.0 & 3.0 & & 100.0 & - \\
817 & 14.5 & 2.3 & & 74.6 & 4.6 \\
818 & - & - & & 36.8 & 4.8 \\
819 & - & - & & 13.2 & 1.3 \\
820 & - & - & & 3.1 & 0.8 \\
\hline
\end{tabular}

$\mathrm{CV}=$ coefficient of variation.

Peaks' heights are normalized prior to $\mathrm{m} / \mathrm{z} 814$ or 816 . 

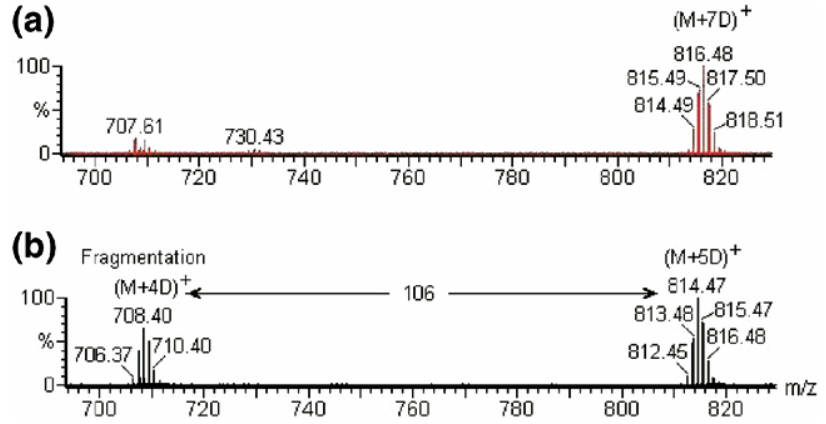

Figure 9. Mass spectra of Leu-Enk labeled with NDA and $\mathrm{N}, \mathrm{N}$-dimethylaminoethanethiol in deuterated eluent. (a) Mass spectra corresponding to the fluorescent peak, (b) mass spectra corresponding to the first peak whose fragments.

stabilized by a hydrogen bond between $\mathrm{C}=\mathrm{O}\left(\mathrm{Tyr}^{1}\right]$ and $\mathrm{N}-\mathrm{H}\left(\mathrm{Gly}^{3}\right)$ like $3_{10}$-helix. The second conformation is similar to the extended form as it is linear without intrachain ${ }^{\circ}$ interactions ${ }^{\circ}\left(\right.$ Figure $\left.^{\circ} 8\right)$. Since ${ }^{\circ}$ the ${ }^{\circ}$ protonation occurs on the side chain, the benzisoindole ring is not affected and the compound can fluoresce. In addition, the proton is too far from the thiol function to obtain an intramolecular rearrangement such as in the previous case, which can explain why there is no fragmentation with the loss of the aminothiol side chain on the derivatized peptide.

In summary, we suggest that the peak at $\operatorname{tr}=9.04$ $\min$ is due to a $\beta$-turn like form, which induced the easy loss of the aminothiol side chain and the loss of fluorescence, while the peak at $\operatorname{tr}=10.00 \mathrm{~min}$ could be represented by an extended conformation or a $3_{10}$-helix form.

\section{H/D Exchange Experiments}

To confirm the above hypotheses and to determine the conformation of the compound at $t_{r}=10.00 \mathrm{~min}$, we studied the H/D exchanges with labeled enkephalin. Water and formic acid of the HPLC eluent were substituted by deuterium oxide and $\mathrm{d}_{2}$-formic acid so that all labile hydrogen could be exchanged with deuterium. It is well documented in the literature that the exchange rate of a labile hydrogen depends on its solvent environment $^{\circ}\left[6,{ }^{\circ} 26^{\circ}, 32,{ }^{\circ} 33\right]^{\circ}$ (i.e., ${ }^{\circ}$ hydrogen $s^{\circ}$ involved $^{\circ}$ in hydrogen bonds or protected from the solvent are less labile than hydrogens exposed to the solvent). If the labeled Leu-Enk is eluted in the deuterated eluent, it is possible to confirm that the difference between the two peaks is due to spatial conforma- tions and to determine them, as previously realized on $^{\circ}$ the ${ }^{\circ}$ native ${ }^{\circ}$ Leu-Enk ${ }^{\circ}[26]$.

$\mathrm{H} / \mathrm{D}$ experiments were repeated three times and the relative abundance of each peak on the mass spectrum with ${ }^{\text {their }}{ }^{\circ}$ variation is ${ }^{\circ}$ summarized in Table 3 . The ${ }^{\circ}$ mass spectra show that mass difference between the two peaks is slightly different; the first peak is predominantly at $m / z=814.5$, which corresponds to an exchange of the 5 atoms of deuterium on the 7 atoms, which ${ }^{\circ}$ are $^{\circ}$ exchangeable $^{\circ}$ (Figure ${ }^{\circ} 9$ ). ${ }^{\circ}$ Two $^{\circ}$ hydrogens ${ }^{\circ}$ are in particularly stable intramolecular bonds; this observation correlates with the $\beta$-turn like conformation where two hydrogen bonds are involved. Moreover, the spectrum presents an ion at $\mathrm{m} / \mathrm{z} 708.4$, which corresponds to the loss of the aminothiol containing one D; the fragment contains 4 deuterium atoms. This result is in accordance with the possible mechanism of fragmentation. The second chromatographic peak occurs at $\mathrm{m} / \mathrm{z}$ 816.5, which indicates that 7 atoms of deuterium are exchanged, i.e., all the labile hydrogens have been exchanged ${ }^{\circ}$ (Figure ${ }^{\circ}$ ) ${ }^{\circ}{ }^{\circ}$ so $^{\circ}$ this ${ }^{\circ}$ second $^{\circ}$ peak ${ }^{\circ}$ would ${ }^{\circ}$ correspond to the extended conformation and not to a stable $3_{10}$-helix conformation. This observation can be explained by the fact that $3_{10}$-helix conformation has not been $^{\circ}$ determined ${ }^{\circ}{ }^{\circ}{ }^{\circ}$ organic $^{\circ}$ solvent $^{\circ}[21]$.

\section{Quantification of Leucine-Enkephalin in Mass Spectrometry}

As the aim of this method is to quantify Leu-Enk in biological samples via mass spectrometry, the generation of a calibration curve for each conformation has been investigated. Calibration curves obtained on the two conformations are linear with acceptable standard deviation on the slope (the standard deviation on the intercept needs to be optimized). LOD with a signal-tonoise of 3 was found to be 0.13 and $0.12 \mu \mathrm{mol} / \mathrm{L}$ for the folded and the unfolded conformation, respectively, when ${ }^{\circ} 10^{\circ} \mu \mathrm{L}^{\circ}$ samples $^{\circ}$ were $^{\circ}$ injected ${ }^{\circ}\left(\right.$ Table $\left.^{\circ} 4\right) .^{\circ}$ This $^{\circ}$ approach for quantifying peptides could be applied even with the phenomenon of the two conformations. However the calibration can be improved by adding an internal standard.

\section{Conclusions}

The mass spectrum of leucine-enkephalin labeled with NDA and N,N-dimethylaminoethanethiol contains two peaks when it is eluted via reverse phase HPLC while only one peak is visible with fluorescence detection. An

Table 4. Results of the quantitation of labelled Leu-Enk with mass detection on the two selected conformations

\begin{tabular}{|c|c|c|c|c|c|c|}
\hline & Equation & $\begin{array}{c}\text { Standard } \\
\text { deviation a }\end{array}$ & $\begin{array}{c}\text { Standard } \\
\text { deviation b }\end{array}$ & $\begin{array}{c}\mathrm{LOD} \\
\mu \mathrm{mol} / \mathrm{L}\end{array}$ & $\mathrm{R}^{2}$ & $\begin{array}{c}\text { Standard } \\
\text { deviation } \mathrm{R}^{2}\end{array}$ \\
\hline Folded labelled Leu-Enk & $y=34.298 x-0.846$ & \pm 6.772 & \pm 3.837 & 0.13 & 0,998 & 0.001 \\
\hline Unfolded labelled Leu-Enk & $y=30.859 x-0.051$ & \pm 3.293 & 2.767 & 0.12 & 0,998 & 0.002 \\
\hline
\end{tabular}

Results were repeated three times at different day. 
explanation to this observation was proposed using molecular modeling and mass spectrometry with H/D exchange. These tools allowed us to demonstrate that the difference between the two peaks is due to two different spatial conformations, corresponding to two different ionization sites; however we cannot demonstrate if the conformations of the peptide moiety induce an isomerization change of the benzisoindole moiety. In addition, a mechanism has been proposed to explain the in-source fragmentation involved in the nonfluorescent folded peptide.

\section{Acknowledgments}

The authors thank Peter Fröhlich for editing the manuscript, and the MRT and Picometrics (Toulouse) for funding of these studies.

\section{References}

1. Hughes, J.; Smith, T. W.; Kosterlitz, H. W. Identification of Two Related Pentapeptides from the Brain with Potent Opiate Agonist Activity. Nature 1975, 258, 577-579.

2. Strand, F. L. Neuropeptides: Regulators of Physiological Processes; MIT Press, Cambridge, MA, 1999, pp. 356-364.

3. Stefano, G. B.; Frichionne, G. L.; Goumon, Y.; Esch, T. Pain, Immunity, Opiate, and Opioid Compounds and Health. Med. Sci. Mon. 2005, 11(5); MS47-MS53.

4. Rinne, O. J.; Lönnberg, P.; Marjamäki, P.; Mölsa, P.; Säkö, E.; Paljärvi, L. Brain Methionine- and Leucine-Enkephalin Receptors in Patients with Dementia. Neurosci. Lett. 1993, 161, 77-80.

5. Qinyang, W.; Lindgren, J. U.; Elhassan, A. M.; Hultenby, K. Distribution of Leucine-Enkephalin in Bone and Joint Tissues. Neuropeptides 2002, 36(4), 281-286

6. Desiderio, D. M.; Zhu X. Quantitative Analysis of Methionine Enkephalin and $\beta$-Endorphin in the Pituitary by Liquid Secondary Ion Mass Spectrometry and Tandem Mass Spectrometry. J. Chromatogr. A 1998, 794, 85-96.

7. Lisi, T. L.; Sluka, K. A. A New Electrochemical HPLC Method for Analysis of Enkephalins and Endomorphins. J. Neurosci. Methods 2006, 150, 74-79.

8. Pacakova, V.; Suchankova, J.; Stulik, K. Separation of Biologically Active Peptides by Capillary Electrophoresis and High-Performance Liquid Chromatography. J. Chromatogr. B 1996, 681, 69-76.

9. Huang, Y.; Duan, J.; Jiang, X.; Chen, H.; Chen, G. Separation and Determination of Enkephalin-Related Peptides Using Capillary Electrophoresis. J. Sep. Sci. 2005, 28, 2534-2539.

10. Lacroix, M.; Poinsot, V.; Fournier, C.; Couderc F. Laser-Induced Fluorescence Detection Schemes for the Analysis of Proteins and Peptides Using Capillary Electrophoresis. Electrophoresis 2005, 26, 2608-2621.

11. Sinnaeve, B. A.; Storme, M. L.; Van Bocxlaer, J. F. Capillary Liquid Chromatography and Tandem Mass Spectrometry for the Quantification of Enkephalins in Cerebrospinal Fluid. J. Sep. Sci. 2005, 28, 1779-1784.

12. Baseski, H. M.; Watson, C. J.; Cellar, N. A.; Shackman, J. G.; Kennedy, R. T. Capillary Liquid Chromatography with $\mathrm{MS}^{3}$ for the Determination of Enkephalins in Microdialysis Samples from the Striatum of Anesthetized and Freely-Moving Rats. J. Mass Spectrom. 2005, 40, 146-153.

13. De Montigny, P.; Riley, C. M.; Sternson, L. A.; Stobaugh, J. F. Fluorogenic Derivatization of Peptides with Naphtalene-2,3-Cicarboxaldehyde/ Cyanide: Optimization of Yield and Application in the Determination of Leucine-Enkephalin Spiked in Human Plasma Samples. J. Pharm. Biomed. Anal. 1990, 8(5), 419-429.
14. Dave, K.; Stobaugh, J. F.; Riley, C. M. Reversed-Phase Liquid Chromatography of the Opioid Peptides. 2. Quantitative Structure-Retention Relationships and Isocratic Retention Prediction. J. Pharm. Biomed. Anal. 1992, 10(1), 49-60.

15. Mifune, M.; Krehbiel, D. K.; Stobaugh, J. F.; Riley, C. M.; MultiDimensional High-Performance Liquid Chromatography of Opioid Peptides Following Precolumn Derivatization with Naphtalene-2,3Dicarboxaldehyde in the Presence of Cyanide Ion. Preliminary Results on the Determination of Leucine- and Methionine-Enkephalin-Like Fluorescence in the Striatum Region of the Rat Brain. J. Chromatogr. $1989,496,55-70$.

16. Carlson, R. G.; Srinivasachar, K.; Givens, R. S.; Matuszewski, B. K. New Derivatizing Agents for Amino Acids and Peptides. 1. Facile Synthesis of N-Substituted 1-Cyanobenz(f)Isoindoles and Their Spectroscopic Properties. J. Org. Chem. 1986, 51, 3978-3983.

17. De Montigny, P.; Stobaugh, J. F.; Givens, R. S.; Carlson, R. G.; Srinivasachar, K.; Sternson, L. A.; Higuchi, T. Naphtalene-2,3-Dicarboxaldehyde/ Cyanide Ion: A Rationally Designed Fluorogenic Reagent for Primary Amines. Anal. Chem. 1987, 59(8), 1096-1101.

18. Yang, J. Z.; Bastian, K. C.; Moore, R. D.; Stobaugh, J. F.; Borchardt, R. T. Quantitative Analysis of a Model Opioid Peptide and Its Cyclic Prodrugs in Rat Plasma Using High-Performance Liquid Chromatography with Fluorescence and Tandem Mass Spectrometric Detection. J. Chromatogr. B 2002, 780, 269-281.

19. Couderc, F., Lacroix, M., Poinsot, V. Method of quantification of primary amines at very low concentration. 2005: French patent FR2890743.

20. Hunter, E. P. L.; Lias, S. G. Evaluated Gas Phase Basicities and Proton Affinities of Molecules: An Update. J. Phys. Chem. Ref. Data 1998, 27, 413-656.

21. Takekiyo, T.; Kato, M.; Taniguchi, Y. FT-IR Spectroscopic Study on Conformational Equilibria of (Leu) ${ }^{5}$-Enkephalin in DMSO and ${ }^{2} \mathrm{H}_{2} \mathrm{O}$ Solutions. J. Mol. Liq. 2005, 119, 147-152.

22. Marcotte, I.; Separovic, F.; Auger, M.; Gagné, S. M. A Multidimensional ${ }^{1} \mathrm{H}$ NMR Investigation of the Conformation of Methionine-Enkephalin in Fast-Tumbling Bicelles. Biophys. J. 2004, 86, 1587-1600.

23. Doi, M.; Tanaka, M.; Ishida, T.; Inoue, M. The Three-Dimensional Similarity Between a Dimeric Antiparallel Extended Structure and a $\beta$-Turn Folded Form of Enkephalin. FEBS Lett. 1987, 213(2), 265-268.

24. Kriz, Z.; Carlsen, P. H. J.; Koca, J. Conformational Features of Linear and Cyclic Enkephalins. A Computational Study. J. Mol. Struct. Theochem. 2001, 540, 231-250.

25. Vengadesan, K.; Gautham, N. Conformational Studies on Enkephalins Using the MOLS Technique. Biopolymers 2004, 74, 476-494.

26. Cai, X.; Dass, C. Structural Characterization of Methionine and Leucine Enkephalins by Hydrogen/Deuterium Exchange and Electrospray Ionization Tandem Mass Spectrometry. Rapid Commun. Mass Spectrom. 2005, 19, 1-8.

27. Ustyuzhanin, P.; Kogan, A.; Reuben, B. G.; Lifshitz, C. An ElectrosprayIonization-Flow-Tube Study of H/D Exchange in Protonated LeucineEnkephalin. Int. J. Chem. Kinet. 2001, 33, 707-714.

28. Jalkanene, K. J. Energetics, Structures, Vibrational Frequencies, Vibrational Absorption, Vibrational Circular Dichroism, and Raman Intensities of Leu-Enkephalin. J. Phys. Condensed Matter 2003, 15, 1823-1851.

29. Abdali, S.; Jensen, M. O.; Bohr, H. Energy Levels and Quantum States of (Leu)Enkephalin Conformations Based on Theoretical and Experimental Investigations. J. Phys. Condensed Matter 2003, 15, 1853-1860.

30. Lakowicz J. R. Principle of Fluorescence Spectroscopy, 2nd ed.; Kluwer Academic/Plenum Publishers: New York, 1999, p. 488.

31. Blancafort, L.; Gonzalez, D.; Olivucci, M.; Robb, M. A. Quenching of Tryptophan ${ }^{1}\left(\pi, \pi^{*}\right)$ Fluorescence Induced by Intramolecular Hydrogen Abstraction Via an Aborted Decarboxylation Mechanism. J. Am. Chem. Soc. 2001, 124, 6398-6406.

32. Lui, H.; Dass, C. Conformational Changes in $\beta$-Endorphin as Studied by Electrospray Ionization Mass Spectrometry. Rapid Commun. Mass Spectrom. 2001, 15, 2341-2346.

33. Sierra, M. D.; Furey, A.; Hamilton, B.; James, M. L.; James, K. J. Elucidation of the Fragmentation Pathways of Azaspiracids, Using Electrospray Ionization, Hydrogen/Deuterium Exchange, and MultipleStage Mass Spectrometry. J. Mass Spectrom. 2003, 38, 1178-1186. 